\title{
The Influence of Culture Medium Components on the Physical and Mechanical Properties of Cellulose Synthesized by Kombucha Microorganisms
}

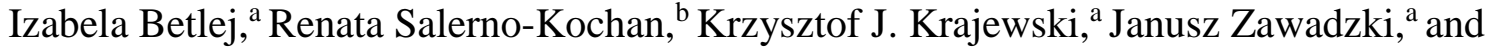 \\ Piotr Boruszewski ${ }^{\text {a, } *}$
}

\begin{abstract}
Preliminary studies are presented showing to what extent nutrients available in the growth environment of Kombucha microorganisms affect the physical and mechanical properties of synthesized cellulose. With an increase in the amount of sucrose in the growth medium and with the presence of additional nutrients, peptone and tea extract, the thickness and strength of the biopolymer increased, while elongation was reduced. The best physical and mechanical parameters were obtained for bacterial cellulose from cultures with the addition of $10 \%$ sucrose and $0.25 \%$ peptone content. The increase in elongation correlated with the decrease in the degree of polymerization, which means that in media rich in nutrients, the number of molecules building the polymer decreases. The presented data is important in order to select ingredients that will help synthesize bacterial cellulose with the desired physio-mechanical properties.
\end{abstract}

Keywords: Bacterial cellulose; Kombucha; SEC analysis; Physical and mechanical properties

Contact information: a: Institute of Wood Sciences and Furniture, Warsaw University of Life Science SGGW, 159 Nowoursynowska St., 02-776 Warsaw, Poland; b: Cracow University of Economics, Department of Nonfood Products Quality and Safety, 4 Sienkiewicza St., 30-033 Kraków, Poland

*Corresponding author: piotr_boruszewski@sggw.pl

\section{INTRODUCTION}

Bacterial cellulose $(\mathrm{BC})$ is an exopolymer composed of glucopyranose $\beta$ 1-4 units. It differs from plant cellulose due to its greater crystallinity (60 to 90\%), mechanical strength, greater purity, lack of lignin and hemicelluloses, high water absorption and retention capacity, higher degree of polymerization, and biocompatibility (da Silva et al. 2015; Fan et al. 2016; Zhao et al. 2018). These features have made bacterial cellulose attractive for potential applications in various industries, such as paper, electronics, cosmetics, and even in the medical and pharmaceutical fields (Khan et al. 2018; Lazarini et al. 2018). The indicated properties of bacterial cellulose make it a favorable raw material for numerous technical materials, thereby improving their mechanical properties. The prospect of such use could be the addition of bacterial cellulose to cellulose fibers or lignocellulosic fibers in wood-based materials in order to strengthen them. An attempt to modify boards by reducing the content of lignin and hemicelluloses through the introduction of bacterial cellulose, would not only create materials with useful physical and mechanical properties, but also reduce the share and consumption of the basic raw material, which is wood. This could be an important direction of research in the aspect of natural resources protection.

Bacterial cellulose is produced by acetic fermentation bacteria, especially by 
Gluconacetobacter xylinus (Huang et al. 2019). A number of other bacteria and yeast fungi also produce cellulose by fermenting sugars contained in the medium under aerobic conditions. These cellulose-producing microorganisms include the bacteria Komagataeibacter xylinus, Acetobacter xylinoides, Gluconobacter oxydans, Gluconacetobacter hansenii, Oenococcus oeni, Komagataeibacter europaeus, and yeast fungi such as Saccharomyces sp., Schizosaccharomyces pombe, Zygosaccharomyces kombuchaensis, or Torulaspora delbrueckii (Teoh et al. 2004; Jayabalan et al. 2010; Marsh et al. 2014; Coton et al. 2017; Villarreal-Soto et al. 2019). Acetobacter xylinum produces two types of cellulose that differ in structure: cellulose I, in which $\beta$ 1-4 glucan chains are linearly arranged, and cellulose II, in which the chains are randomly arranged (Yu and Atalla 1996; Skočaj 2019).

Cellulose synthesis in experimental conditions can be carried out in static and dynamic cultures. The cellulose produced by microorganisms in static cultures is synthesized in the form of a film on the surface of the medium solution. The thickness of the film varies depending on the nutrients and breeding time (Torgbo and Sukyai 2018). Under dynamic culture conditions, cellulose is produced in the form of granules. Cellulose synthesis in dynamic culture conditions is faster; however, the properties of such cellulose differ from those of cellulose produced in stationary conditions (Shah et al. 2013). The cellulose synthesized by bacteria in its molecular structure has the form of a mesh swollen with water, with a fiber length of approximately $100 \mu \mathrm{m}$ and a microfibril that does not exceed 2 to $4 \mathrm{~nm}$ (Klemm et al. 2006; Nogi and Yano 2009; Stanisławska 2016). The biopolymer's mesh structure allows it to be a good matrix for absorbing various chemical compounds, both organic polymers, and inorganic nanocompounds (Khan et al. 2015; Khan et al. 2018; Patwa et al. 2019).

Both wet and dried biocellulose have advantageous mechanical properties (Bäckdahl et al. 2006). The tensions at break are analogous to steel, and the tensile strength is approximately 100 times higher than that of polypropylene (Yano et al. 2005; Gatenholm and Klemm 2010). These properties of bacterial cellulose make it a suitable reinforcement for improving mechanical properties in numerous technical materials. Related studies have been conducted on the use of bacterial cellulose to strengthen paper produced from waste paper (Campano et al. 2018) and other types of paper made of low quality fiber (Skočaj 2019). Therefore, bacterial cellulose could also be used to strengthen cellulose or lignocellulosic fibers in wood-based materials, although scientific literature does not yet indicate any attempts to study such use.

The unique properties of bacterial cellulose depend not only on the strain of microorganisms, but primarily on the culture conditions, including the composition of the culture medium (Illa et al. 2019). Chen et al. (2019) studied the effect of mono- and disaccharides on the efficiency of cellulose synthesis by Komagataeibacter xylinus, while Illa et al. (2019) assessed the effect of drying conditions on the physical, chemical, and morphological properties of cellulose.

The effect of nutrients contained in the growth medium of microorganisms belonging to Gluconacetobacter on the physio-mechanical properties of the cellulose produced has been the subject of numerous studies, but there is little data in the literature regarding the influence of substrate components on the quality and properties of cellulose synthesized by Kombucha biofilm microorganisms. Kombucha is a set of microorganisms used in beverage fermentation processes, particularly in tea, fruit juice, and herbal drinks fermentation. The impact of sucrose on the cellulose synthesis efficiency of Kombucha microorganisms was assessed by Al-Kalifawi (2014), while 
Domskiene et al. (2019) analyzed the mechanical properties of cellulose synthesized by Kombucha in terms of its use in the textile industry.

This paper presents preliminary results of the assessment of the effect of nutrient composition, in particular various sucrose concentrations, and addition of tea and peptone extract on the physical and mechanical properties of cellulose synthesized by Kombucha microorganisms. Peptone is the main component of organic nitrogen, while tea extract contains numerous organic compounds such as vitamins, alkaloids, essential oils, amino acids, and dyes as well as inorganic compounds including salts of magnesium, iron, silicon, and potassium. Tea extract and peptone concentrations were selected based on a preliminary analysis of the literature on the content of nutrients in cultures of Kombucha microorganisms (Joshi and Kumar 2017; Sharma and Bhardwaj 2019). The adopted assumptions could help in determining the medium composition for growing Kombucha microorganisms in order to synthesize cellulose with the best properties. The obtained cellulose could be used as a filler in lignocellulosic composites.

\section{EXPERIMENTAL}

\section{Materials}

The effect of nutrients on select physical and mechanical characteristics of cellulose synthesized by Kombucha, acetic fermentation microorganisms, was assessed in three types of media (Table 1). Each type of media contained sucrose in various proportions: $2.5 \%, 5 \%$, and $10 \%$. In addition, one variant of the medium was enriched with $0.25 \%$ peptone content (Biomaxima, Lublin, Poland), while the other contained $0.1 \%$ Camellia sinensis tea extract (Sigma-Aldrich, Taufkirchen, Germany). The reference media were samples containing only sucrose at various concentrations. The incubation of microorganisms was carried out in stationary culture at temperature and humidity conditions of $24{ }^{\circ} \mathrm{C}$ and $68 \pm 2 \%$, respectively. The cultivation time of the cellulose synthesizing microorganisms was 14 days. After the planned cultivation time, the cellulose produced was collected and prepared for further research. The obtained cellulose sample was rinsed thoroughly in detergent, rinsed twice in distilled water, rinsed in $0.1 \% \mathrm{NaOH}$ (POCH, Gliwice, Poland), and rinsed in distilled water. Next, cellulose was washed in $0.1 \%$ citric acid (POCH, Gliwice, Poland) and again, twice in distilled water. This treatment reduced cellulose microorganisms and adjusted the $\mathrm{pH}$ of the cellulose to neutral. The samples were dried for $12 \mathrm{~h}$ at $60{ }^{\circ} \mathrm{C}$ down to $5 \pm 1 \%$ moisture content. Dried cellulose samples were stored in a desiccator until testing.

Table 1. Culture Media Used in the Research

\begin{tabular}{|c|c|c|c|}
\hline Variant & Sucrose (\%) & Peptone (\%) & Tea extract (\%) \\
\hline A2.5 & 2.5 & \multirow{2}{*}{0} & 0 \\
\hline A5 & 5.0 & & \multirow{2}{*}{0.1} \\
\hline A10 & 10.0 & 0 & \\
\hline B2.5 & 2.5 & & \multirow{2}{*}{0} \\
\hline B5 & 5.0 & \multirow{2}{*}{0.25} & \\
\hline B10 & 10.0 & & \\
\hline C2.5 & 2.5 & & \\
\hline C5 & 5.0 & & \\
\hline C10 & 10.0 &
\end{tabular}




\section{Methods}

Tensile strength tests

Tensile tests on the bacterial cellulose were carried out using an Instron 5544 testing machine (Instron, High Wycombe, UK). The tensile strength, expressed in $\mathrm{N} / \mathrm{mm}^{2}$, and elongation at break, expressed in $\mathrm{mm}$, were determined. Test samples were prepared in accordance with the guidelines of ISO 527-3 (2018). Tensile tests of bacterial cellulose were conducted based on ISO 527-1 (2019). Samples of bacterial cellulose dried to a constant weight had the shape of rectangles measuring $80 \times 25 \mathrm{~mm}$. At an equal distance from the narrower edges, a measuring section with a length of $50 \mathrm{~mm}$ was determined. Tensile tests were carried out at a head speed of $10 \mathrm{~mm} / \mathrm{min}$. Before measuring the tensile strength, the thickness of the bacterial cellulose samples was measured using an Extramess 2000 thickness gauge (Mahr, Göttingen, Germany). The mechanical properties given correspond to the mean values of at least five measurements.

\section{Statistical analysis}

Statistical analyses were developed using Statistica version 13.3 software (StatSoft, Inc., Tulsa, OK, USA). The statistical analysis of the results was based on a two-factor ANOVA analysis of variance. The significance of the hypothesis was tested by Tukey's test. The relationship between variables was determined in a correlation test.

\section{RESULTS AND DISCUSSION}

The thickness of cellulose produced by Kombucha microorganisms increased with increases in the amounts of sucrose, peptone, and tea extract in the medium. The thickness of the obtained cellulose samples ranged from 0.04 to $0.46 \mathrm{~mm}$ and depended on the type of ingredients present in the medium (Fig. 1).

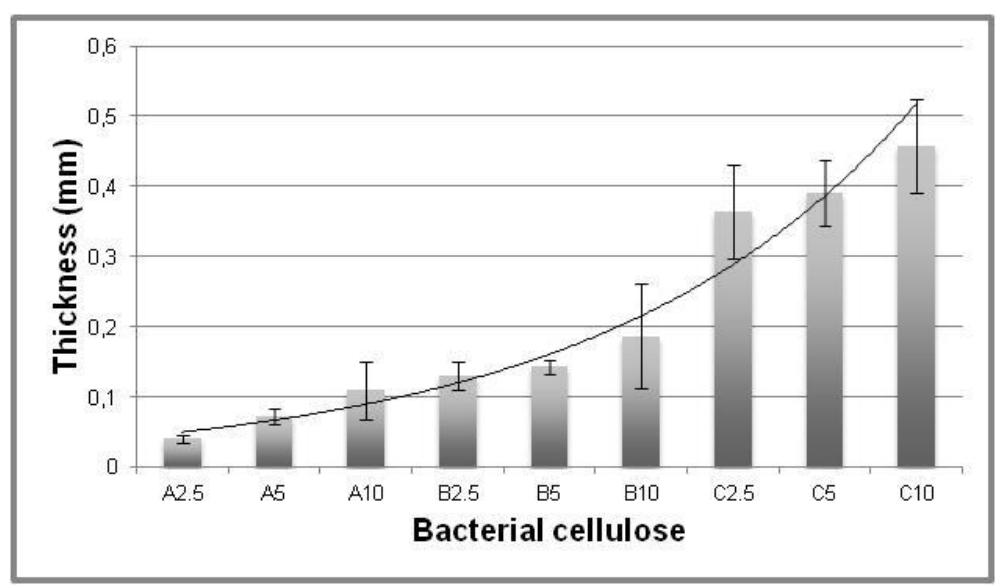

Fig. 1. Thickness of bacterial cellulose, produced by Kombucha microorganisms, growing on a substrate with different sucrose content and the presence of peptone and tea extract

Films obtained from the cellulose produced in the media containing only sucrose (samples A) had the lowest thickness, while increased amount of carbon in sucrose (from 2.5 to $10 \%$ ), increased the thickness of the film. The presence of peptone and tea extract in the media (samples B and C) increased the thickness of the samples. The thickness of the samples produced under these conditions was greater than in the media with sucrose 
alone. Samples obtained from cellulose produced in media containing $0.25 \%$ peptone in addition to the sucrose (samples C) were characterized by the greatest thickness (Fig. 1). The obtained results are partly consistent with the research of other authors (Sharma and Bhardwaj 2019), who pointed out that the efficiency of cellulose synthesis increases with the content of sugar in the growth medium. They stated however, that there is some sugar concentration (above 5\%) at which the efficiency of polymer synthesis begins to decrease, which was not observed in this experiment.

The content of sucrose in the growth medium of microorganisms had a significant impact on the tensile strength of bacterial cellulose films. More sugar in the medium resulted in better strength of the polymer (Fig. 2). Cellulose samples obtained from media containing $10 \%$ sucrose were almost 20 times as strong as samples obtained from media containing $2.5 \%$ and $5 \%$ sucrose. Although the values of tensile strength of the synthesized cellulose was not very high, it was noticed that the presence of additional components in the growth medium of Kombucha microorganisms had a significant impact on the strength of cellulose films. Statistical analysis showed a high correlation between the medium composition and the tensile strength (Table 3). Numerous authors have obtained results of bacterial cellulose strength at the level of several dozen $\mathrm{MPa}$; however, many factors influence these properties (Krystynowicz et al. 2002; Illa et al. 2019). Statistically significant differences were found in tests for cellulose tensile strength between different culture media used in the study. Individual nutrient components had a significant impact on the values of the examined characteristic (Tab. 2). Cellulose obtained from media containing $2.5 \%$ peptone was up to $400 \%$ more durable compared to cellulose obtained from media containing the same amount of sucrose only, and 60\% more durable compared to samples obtained from media containing the same sucrose content and $0.1 \%$ tea extract content (Fig. 2).

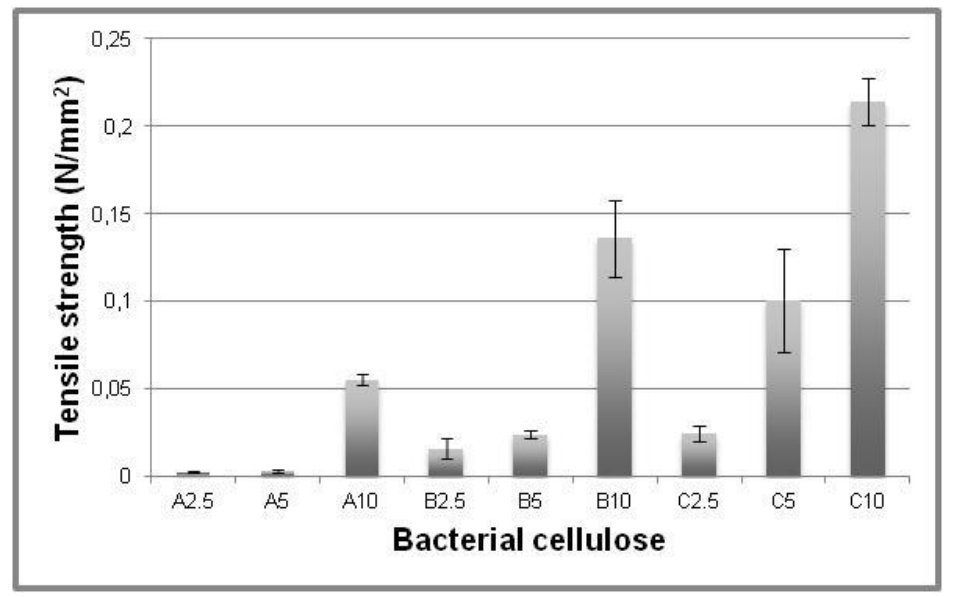

Fig. 2. Tensile strength of bacterial cellulose, produced by Kombucha microorganisms, growing on a substrate with different sucrose content and the presence of peptone and tea extract

When analyzing the elongation of bacterial cellulose samples, a large variation in the measured values of the tested samples was observed (Fig. 3). The elongation of the tested cellulose film samples ranged from $2.9 \mathrm{~mm}$ to approximately $19.2 \mathrm{~mm}$ and depended on the sucrose content as well as the content of other additives in the medium. It should be added that the obtained values of elongation are typical for cellulosic materials, which are characterized by a low elongation. The presence of substances such 
as peptone or tea extract in a culture medium may, however, affect the chemical structure and degree of cellulose polymerization. With increased sucrose content in the medium, the average elongation values of cellulose samples decreased, and the lowest value was obtained for cellulose samples prepared on media containing 10\% sucrose (without additives). The presence of additives (peptone, tea extract) in the medium increased the elongation value of the film samples (Fig. 3).

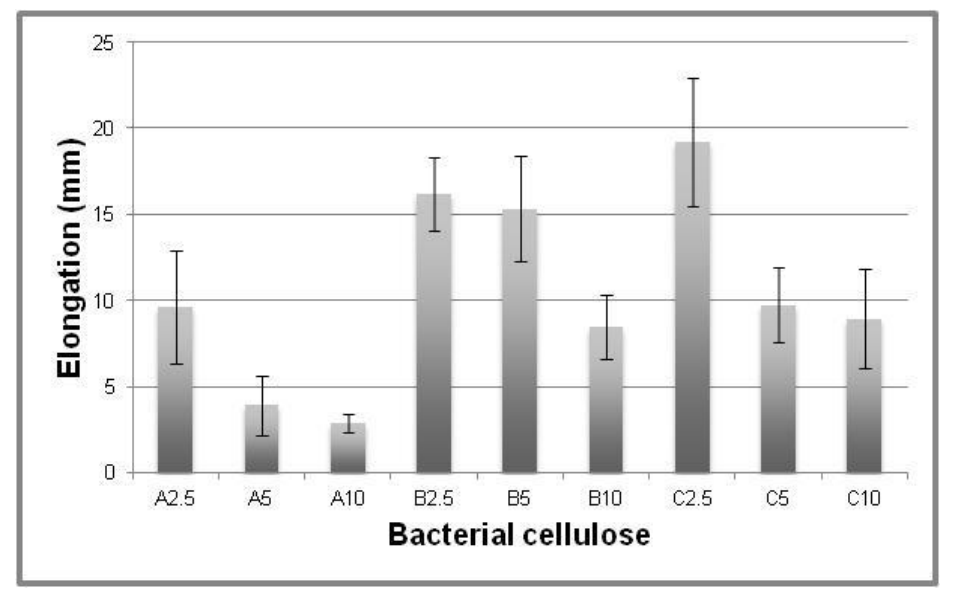

Fig. 3. The average result of the elongation of bacterial cellulose, produced by Kombucha microorganisms, growing on a substrate with different content of carbon and nitrogen sources

Table 2. Assessment of the Interaction between Different Types of Culture Media in Relation to the Examined Characteristics of the Bacterial Cellulose

\begin{tabular}{|c|c|c|c|c|c|c|c|}
\hline \multirow[b]{2}{*}{ Specification } & \multirow[b]{2}{*}{$\begin{array}{c}\text { Sucrose } \\
\text { content } \\
(\%)\end{array}$} & \multicolumn{3}{|c|}{ Type } & \multicolumn{3}{|c|}{ Statistical impact } \\
\hline & & Sucrose & $\begin{array}{c}\text { Sucrose }+ \\
0.1 \% \text { tea } \\
\text { extract }\end{array}$ & $\begin{array}{c}\text { Sucrose + } \\
0.25 \% \\
\text { peptone }\end{array}$ & $P$ & $\mathrm{R}$ & PxR \\
\hline \multirow{3}{*}{ Strength } & 2.5 & $\begin{array}{c}{ }^{x \times} 0,00237 \\
\pm 0,00022^{a A}\end{array}$ & $\begin{array}{l}{ }^{x} \times 0,01561 \\
\pm 0,00590^{b}\end{array}$ & $\begin{array}{c}{ }^{x} \times 0,02485 \\
\pm 0,00465^{b B}\end{array}$ & \multirow{3}{*}{ * } & \multirow{3}{*}{ * } & \multirow{3}{*}{ * } \\
\hline & 5.0 & $\begin{array}{c}x \times 0,00298 \\
\pm 0,00069 \mathrm{aA}\end{array}$ & $\begin{array}{c}{ }^{x} \times 0,02364 \\
\pm 0,00220^{a A}\end{array}$ & $\begin{array}{c}\mathrm{yY}^{\mathrm{Y}} 0,10035 \\
\pm 0,02951^{\mathrm{bB}}\end{array}$ & & & \\
\hline & 10.0 & $\begin{array}{c}{ }^{\mathrm{Y}} 0,05526 \\
\pm 0,00292^{\mathrm{aA}}\end{array}$ & $\begin{array}{c}\mathrm{yY}^{\mathrm{Y}} 0,13800 \\
\pm 0,02215^{\mathrm{bB}}\end{array}$ & $\begin{array}{c}\mathrm{zZ} 0,21927 \\
\pm 0,01371^{\mathrm{cC}}\end{array}$ & & & \\
\hline \multirow{3}{*}{ Thickness } & 2.5 & $\begin{array}{c}x \times 0,04055 \\
\pm 0,00614^{\mathrm{aA}}\end{array}$ & $\begin{array}{c}0,13000 \\
\pm 0,02066^{\mathrm{bB}}\end{array}$ & $\begin{array}{c}{ }^{x} 0,36443 \\
\pm 0,06717 \mathrm{cc}\end{array}$ & \multirow{3}{*}{ * } & \multirow{3}{*}{ * } & \multirow{3}{*}{$\begin{array}{c}N S \\
(P=0.85)\end{array}$} \\
\hline & 5.0 & $\begin{array}{c}0,07190 \\
\pm 0,01086^{\mathrm{aA}} \\
\end{array}$ & $\begin{array}{c}0,14283 \\
\pm 0,00939 \mathrm{bB} \\
\end{array}$ & $\begin{array}{c}0,39033 \\
\pm 0,04702^{c c} \\
\end{array}$ & & & \\
\hline & 10.0 & $\begin{array}{c}{ }^{{ }^{\mathrm{Y}}} 0,10958 \\
\pm 0,04055^{\mathrm{aA}}\end{array}$ & $\begin{array}{c}0,18683 \\
\pm 0,07394^{a \mathrm{~A}}\end{array}$ & $\begin{array}{c}\mathrm{y}^{\mathrm{y}} 0,45743 \\
\pm 0,06613^{\mathrm{bB}}\end{array}$ & & & \\
\hline \multirow{3}{*}{ Elongation } & 2.5 & $\times 9,63 \pm 3,27 \mathrm{aA}$ & $\times 16,17 \pm 2,12$ & $\mathrm{xX} 19,21 \pm 3,69^{\mathrm{bB}}$ & \multirow{3}{*}{ * } & \multirow{3}{*}{ * } & \multirow{3}{*}{ * } \\
\hline & 5.0 & $\mathrm{y} 3,92 \pm 1,71^{\mathrm{aA}}$ & $\mathrm{xx} 15,34 \pm 3,09^{\mathrm{bB}}$ & yY9,73 $\pm 2,18^{c}$ & & & \\
\hline & 10.0 & $\mathrm{y} 2,89 \pm 0,51^{\mathrm{a}}$ & $\mathrm{yY}^{\mathrm{Y}} 8,47 \pm 1,86^{\mathrm{b}}$ & $\mathrm{yY}^{\prime} 8,94 \pm 2,85^{\mathrm{b}}$ & & & \\
\hline
\end{tabular}

Notes:

* statistically significant impact $(P<0.05)$; NS statistically insignificant impact $(P>0.05)$

a, b, $C$ - values in rows marked with different letters differ statistically significantly $(P<0.05)$;

$A, B, C$ - the values in the lines marked with different letters differ statistically $(P<0.01)$;

$\mathrm{X}, \mathrm{y}, \mathrm{z}$ - values in columns for a given feature marked with different letters differ statistically significantly $(\mathrm{P}<0.05) ; \mathrm{X}, \mathrm{Y}, \mathrm{Z}$ - values in columns for a given feature marked with different letters differ statistically $(P<0.01) ; P$ - content $\%(2.5 ; 5 ; 10)$; R- (sucrose, sucrose $+0.1 \%$; sucrose $+0.25 \%$ ) 
Table 3. Correlation Results between Individual Components of the Culture Medium and the Examined Features of the Bacterial Cellulose

\begin{tabular}{|c|c|c|c|}
\hline Specification & Sucrose & $\begin{array}{c}\text { Sucrose }+0.1 \% \text { tea } \\
\text { extract }\end{array}$ & $\begin{array}{c}\text { Sucrose }+0.25 \% \\
\text { peptone }\end{array}$ \\
\hline Strength & $r(X, Y)=0.887$ & $r(X, Y)=0.878$ & $r(X, Y)=0.967$ \\
\hline Thickness & $r(X, Y)=0.766$ & $r(X, Y)=0.451 n s$ & $r(X, Y)=0.541$ \\
\hline Elongation & $r(X, Y)=0.742$ & $r(X, Y)=0.797$ & $r(X, Y)=0.713$ \\
\hline
\end{tabular}

The composition of the medium has been found to have a large impact on the physiochemical and mechanical properties of bacterial cellulose (Chen et al. 2019; Gayathri and Srinikethan 2019). The properties of bacterial cellulose change depending on the microbial culture conditions (Santos et al. 2013). The nitrogen content in the substrate and its source determine the physio-mechanical properties of cellulose, which is confirmed by studies by Santos et al. (2013) and Yim et al. (2017). The amount of carbon source also determines characteristics such as tensile strength. With increased sucrose content in the substrate, an increase in tensile strength of the synthesized cellulose was observed, although some researchers observed a decrease in strength, with sugar content above 5\% (Yim et al. 2017). Bacterial cellulose is in fact synthesized with the participation of enzymes, which can have their activity modified by the $\mathrm{pH}$ of the environment, inhibitors, and chemical activators (Tahara et al. 2014). It can, therefore, be concluded that the various concentrations of sucrose used may act as activators or inhibitors of the enzymes responsible for cellulose synthesis, which requires confirmation in further studies. Therefore, it seems that the influence of the substrate components may be of significant importance in the quality of synthesized cellulose. The addition of peptone or tea extract can be treated as a supplementation necessary to obtain better polymer strength parameters. It is possible that the effects of the ingredients on changes in strength parameters, degree of elongation or thickness of the polymer can be traced in their impact on the metabolism of the studied microorganisms. It is known that various components in the growth medium can trigger specific cellulose synthase operons in the cellular genome, thereby causing polymer synthesis with different characteristics ( $\mathrm{Lu}$ et al. 2020). It seems, therefore, that this is how the phenomenon of the influence of substrate components on the properties of synthesized cellulose should be interpreted.

\section{CONCLUSIONS}

1. The amount of synthesized bacterial cellulose and its physical and mechanical properties strongly depend on the type of cellular medium on which they grow.

2. With the increase in amount of sucrose and ingredients in the medium, the thickness of the cellulose films increase.

3. The addition of peptone and tea extract to the growth medium of Kombucha microorganisms improves both the strength properties of the cellulose as well as the elongation. 


\section{ACKNOWLEDGMENTS}

The authors thank Warsaw University of Life Sciences - SGGW for their financial support.

\section{REFERENCES CITED}

Al-Kalifawi, E. J. (2014). "Produce bacterial cellulose of kombucha (Khubdat Humza) from honey," Journal of Genetic and Environmental Resources Conservation 2(1), $39-45$.

Bäckdahl, H., Helenius, G., Bodin, A., Johansson, B., Nanmark, U., Risberg, B., and Gatenholm, P. (2006). "Bacterial cellulose as potential scaffold for tissue engineered blood vessels: mechanical properties and cell interactions," Biomaterials 27(9), 21412149. DOI: $10.1016 /$ j.biomaterials.2005.10.026

Campano, C., Merayo, N., Negro, C., and Blanco, A. (2018). "Low-fibrillated bacterial cellulose nanofibers as a sustainable additive to enhance recycled paper quality," International Journal of Biological Macromolecules 114(9), 1077-1083. DOI: 10.1016/j.ijbiomac.2018.03.170

Chen, G., Wu, G., Chen, L., Wang, W., Hong, F. F., and Jonsson, L. J. (2019).

"Comparison of productivity and quality of bacterial nanocellulose synthesized using culture media based on seven sugars from biomass," Microbial Biotechnology 12(4), 677-687. DOI:10.1111/1751-7915.13401

Coton, M., Pawtowski, A., Taminiau, B., Burgaud, G., Deniel, F., Coulloumme Labarthe, L., Fall, A., Daube, G., and Coton, E. (2017). "Unraveling microbial ecology of industrial scale Kombucha fermentations by metabarcoding and culture-based methods," FEMS Microbiology Ecology 93(5), 1-16. DOI: 10.1093/femsec/fix048

da Silva, C. M., Karspinki Bottene, M., de Oliveira Barud, H. G., da Silva Barud, H., Ligabuee, R. A., and Jahno, V. D. (2015). "Wettability and morphological characterization of a polymeric bacterial cellulose/corn starch membrane," Materials Research 18(2), 109-113. DOI: 10.1590/1516-1439.351214

Domskiene, J., Sederaviciute, F., and Simonaityte, J. (2019). "Kombucha bacterial cellulose for sustainable fashion," International Journal of Clothing Science and Technology 31(5), 644-652. DOI: 10.1108/IJCST-02-2019-0010

Fan, X., Gao, Y., He, W., Hu, H., Tian, M., Wang, K., and Pan, S. (2016). "Production of nano bacterial cellulose from beverage industrial waste of citrus peel and pomace using Komagataeibacter xylinus," Carbohydrate Polymers 151(17), 1068-1072. DOI: 10.1016/j.carbpol.2016.06.062

Gatenholm, P., and Klemm, D. (2010). "Bacterial nanocellulose as a renewable material for biomedical applications," MRS Bulletin 35(3), 208-213. DOI: $10.1557 / \mathrm{mrs} 2010.653$

Gayathri, G., and Srinikethan, G. (2019). "Bacterial cellulose production by $K$. saccharivorans $\mathrm{BC} 1$ strain using crude distillery effluent as cheap and cost effective nutrient medium," International Journal of Biological Macromolecules 138(18), 950957. DOI: 10.1016/j.ijbiomac.2019.07.159

Huang, C., Ji, H., Guo, B., Luo, L., Xu, W., Li, J., and Xu, J. (2019). “Composite nanofiber membranes of bacterial cellulose/halloysite nanotubes as lithium ion battery separators," Cellulose 26(11), 6669-6681. DOI: 10.1007/s10570-019-02558-y 
Illa, M. P., Sharma, C. S., and Khandelwal M. (2019). "Tuning the physiochemical properties of bacterial cellulose: Effect of drying conditions," Journal of Materials Science 54(18), 12024-12035. DOI: 10.1007/s10853-019-03737-9

ISO 527-1 (2019). "Plastics - Determination of tensile properties - Part 1: General principles," International Organization for Standardization, Geneva, Switzerland.

ISO 527-3 (2018). "Plastics - Determination of tensile properties - Part 3: Test conditions for films and sheets," Organization for Standardization, Geneva, Switzerland.

Jayabalan, R., Baskaran, S., Marimuthu, S., Swaminathan, K., and Yun, S. E. (2010). "Effect of kombucha tea on aflatoxin B1 induced acute hepatotoxicity in albino ratsprophylactic and curative studies," Journal of Applied Biological Chemistry 53(4), 407-416. DOI: 10.3839/jksabc.2010.063

Joshi, V.K., and Kumar, V. (2017). "Influence of different sugar sources, nitrogen sources and inocula on the quality characteristics of apple tea wine," Journal of the Institute of Brewing 123(2), 268-276. DOI: 10.1002/jib.417

Khan, S., Ul-Islam, M., Khattak, W. A., Ullah, M. W., and Park J. K. (2015). "Bacterial cellulose-titanium dioxide nanocomposites: Nanostructural characteristics, antibacterial mechanism, and biocompatibility," Cellulose 22(1), 565-579. DOI: 10.1007/s10570-014-0528-4

Khan, S., Ul-Islam, M., Ullah, M. W., Israr, M., Jang, J. H., and Park, J. K. (2018). "Nano-gold assisted highly conducting and biocompatible bacterial cellulosePEDOT:PSS films for biology-device interface applications," International Journal of Biological Macromolecules 107(2), 865-873. DOI: 10.1016/j.ijbiomac.2017.09.064

Klemm, D., Schumann, D., Kramer, F., Heßler, N., Hornig, M., Schmauder, H. P., and Marsch S. (2006). "Nanocelluloses as innovative polymers in research and application," Advances in Polymer Science 205(1), 49-96. DOI: 10.1007/12_097

Krystynowicz, A., Czaja, W., Jezierska, A.W., Gonçalves-Miśkiewicz, M., Turkiewicz, M., and Bielecki, S. (2002). "Factors affecting the yield and properties of bacterial cellulose," Journal of Industrial Microbiology \& Biotechnology 29(6), 189-195. DOI: 10.1038/sj.jim.7000303

Lazarini, S. C., Yamada, C., Barud, H. S., Trovatti, E., Corbi, P. P., and Lustri, W. R. (2018). "Influence of chemical and physical conditions in selection of Gluconacetobacter hansenii ATCC 23769 strains with high capacity to produce bacterial cellulose for application as sustained antimicrobial drug-release supports," Applied Microbiology 125(3), 777-791. DOI: 10.1111/jam.13916

Lu, T., Gao, H., Liao, B., Wu, J., Zhang, W., Huang, J., Liu, M., Huang, J., Chang, Z., Jin, M., Yi, Z., and Jiang, D. (2019). "Characterization and optimization of production of bacterial cellulose from strain CGMCC 17276 based on whole-genome analysis," Carbohydrate Polymers 232(1), 1-14. DOI: 10.1016/j.carbpol.2019.115788

Marsh, A. J., O'Sullivan, O., Hill, C., Ross, R. P., and Cotter, P. D. (2014). "Sequencebased analysis of the bacterial and fungal compositions of multiple kombucha (tea fungus) samples," Food Microbiology 38(2), 171-178. DOI: 10.1016/j.fm.2013.09.003

Nogi, M., and Yano, H. (2009). "Transparent nanocomposites based on cellulose produced by bacteria offer potential innovation in the electronics device industry," Advanced Materials 20(10), 1849-1852. DOI: 10.1002/adma.200702559 
Patwa, R., Saha, N., Sáha, P., and Katiyar, V. (2019). "Biocomposites of poly(lactic acid) and lactic acid oligomer-grafted bacterial cellulose: It's preparation and characterization," Journal of Applied Polymer Science 136(35), 1-13. DOI: 10.1002/app.47903 10.1002/APP.47903

Santos, S. M., Carbajo, J. M., and Villar, J. C. (2013). "The effect of carbon and nitrogen sources on bacterial cellulose production and properties from Gluconacetobacter sucrofermentans CECT 7291 focused on its use in degraded paper restoration," BioResources 8(3), 3630-3645. DOI: 10.15376/biores.8.3.3630-3645

Shah, N., Ul-Islam, M., Khattak,W. A., and Park, J. K. (2013). "Overview of bacterial cellulose composites: A multipurpose advanced material," Carbohydrate Polymers 98(2), 1585-1598. DOI: 10.1016/j.carbpol.2013.08.018

Sharma, C., and Bhardwaj, N. K. (2019): "Biotransformation of fermented black tea into bacterial nanocellulose via symbiotic interplay of microorganisms," International Journal of Biological Macromolecules 132(12), 166-177. DOI: 10.1016/j.ijbiomac.2019.03.202

Skočaj, M. (2019). "Bacterial nanocellulose in papermaking," Cellulose 26(11), 64776488. DOI: 10.1007/s10570-019-02566-y

Stanisławska, A. (2016). "Bacterial nanocellulose as a microbiological derived nanomaterial," Advances in Materials Science 16(4), 45-57. DOI: 10.1515/adms2016-0022

Tahara, N., Tabuchi, M., Watanabe, K., Yano, H., Morinaga, Y., and Yoshinaga, F. (2014). "Degree of polymerization of cellulose from Acetobacter xylinum BPR2001 decreased by cellulase produced by the strain," Bioscience, Biotechnology, and Biochemistry 61(11), 1862-1865. DOI: 10.1271/bbb.61.1862

Teoh, A. L., Heard, G., and Cox, J. (2004). "Yeast ecology of Kombucha fermentation," International Journal of Food Microbiology 95(2), 119-126. DOI:10.1016/j.ijfoodmicro.2003.12.020

Torgbo, S., and Sukyai, P. (2018). "Bacterial cellulose-based scaffold materials for bone tissue engineering," Applied Materials Today 11(2), 34-49. DOI:

10.1016/j.apmt.2018.01.004

Yano, H., Sugiyama, J., Nakagaito, A. N., Nogi, M., Matsura, T., Hikita, H., and Handa, K. (2005). "Optically transparent composites reinforced with networks of bacterial nanofibers," Advanced Materials 17(2), 153-155. DOI: 10.1002/adma.200400597

Yim, S. M., Song, J. E., and Kim, H. R. (2017). "Production and characterization of bacterial cellulose fabrics by nitrogen sources of tea and carbon sources of sugar," Process Biochemistry 59(8), 26-36. DOI: 10.1016/j.procbio.2016.07.001

$\mathrm{Yu}$, X., and Atalla, R. H. (1996). "Production of cellulose II by Acetobacter xylinum in the presence of 2,6-dichlorobenzonitrile," International Journal of Biological Macromolecules 19(3), 145-146. DOI: 10.1016/0141-8130(96)01109-9

Villarreal-Soto, S. A., Beaufort, S., Bouajila, J., Souchard, J. P., Renard, T., Rollan, S., and Taillandier, P. (2019). "Impact of fermentation conditions on the production of bioactive compounds with anticancer, anti-inflammatory and antioxidant properties in Kombucha tea extracts," Process Biochemistry 83(8), 44-54. DOI:

10.1016/j.procbio.2019.05.004 
Zhao, H., Xiac, J., Wang, J., Yan, X., Wang, C., Lei, T., Xian, M., and Zhang, H. (2018). "Production of bacterial cellulose using polysaccharide fermentation wastewater as inexpensive nutrient sources," Biotechnology \& Biotechnological Equipment 32(2), 350-356. DOI: 10.1080/13102818.2017.1418673

Article submitted: December 18, 2019; Peer review completed: February 14, 2020;

Revised version received: February 25, 2020; Accepted: February 27, 2020; Published: March 18, 2020.

DOI: $10.15376 /$ biores.15.2.3125-3135 